\title{
Expanded and Nano-Structured Carbonaceous Graphite for High Performance Anisotropic Fuel Cell Polymer Composites
}

\author{
Nazmus Saadata ${ }^{a}$, Hom N. Dhakalc, Shaffiq Jaffer ${ }^{\mathrm{d}}$, Jimi Tjong ${ }^{\mathrm{b}}$, Wemin Yang ${ }^{\mathrm{e}}$, Jing Tan ${ }^{\mathrm{b}}$,
} Mohini Sain ${ }^{\mathrm{a}, \mathrm{b}}$

\footnotetext{
${ }^{a}$ Centre for Biocomposites and Biomaterials Processing, Division of Forestry, Daniels Faculty of Architecture, Landscape and Design, University of Toronto, Toronto, Ontario, Canada

bepartment of Mechanical and Industrial Engineering, University of Toronto, Toronto, Ontario, Canada

'Advanced Materials and Manufacturing (AMM) Research Group, School of Mechanical and Design Engineering, University of Portsmouth, Portsmouth, England, United Kingdom

${ }^{\mathrm{d}}$ Total NA, Hopkinton MA, USA

${ }^{\mathrm{e}}$ College of Industrial Engineering, Beijing University of Chemical Technology, Beijing, China
}

\section{Abstract:}

We disclose novel high pressure design, non-destructive structural analysis and fabrication of bipolar plate composites (BPC) that are highly conductive yet mechanically flexible. Here we report the highest electrical conductivity of $221{\mathrm{~S} . \mathrm{cm}^{-1}}^{-1}$ of a BPC by tailoring graphitic structure of carbon nanomaterials and their functional attributes through enhancement of in-plane conductivity as well as mechanical strength; another advanced BPC also displays a maximum flexural strength of $52 \mathrm{MPa}$. These key functional efficiency enhancements of hydrogen based electric power trains components became highly relevant for medium to heavy duty transportation. Evidently, tunable, expandable and expanded graphitic composites can play a major role in facilitating the fabrication of a light-weight high-performance plates for fuel cell application.

Keywords: Multifunctional composites; Graphene; Electrical properties; Mechanical properties; Fuel cell

\section{* Corresponding author:}

Mohini M. Sain (m.sain@utoronto.ca)

Tel: +16477066011 ; fax: +14169783834 


\section{INTRODUCTION:}

29 Proton exchange membrane fuel cell (PEMFC), the most used fuel cell in transportation sector, has advantages of low operating temperature, relatively fast start-up process, and high-energy

31 density over other electrochemical devices. Hence, PEMFC becomes the most promising and 32 vastly researched fuel cell. They have three main components, bipolar plates (BPP), gas diffusion layer (GDL) and membrane electrode assembly (MEA) (Fig. 1). BPP which can be made from

34 graphite, metal or carbon polymer composite is a very important part because they can contribute up to $60-80 \%$ of the total weight as well as $30-40 \%$ of the total stack cost [1-4]. Their main functions include connecting the adjacent cells, distribution of fuel gas, removing heat and water,

37 and supporting the MEA sustaining the clamp pressure [5].

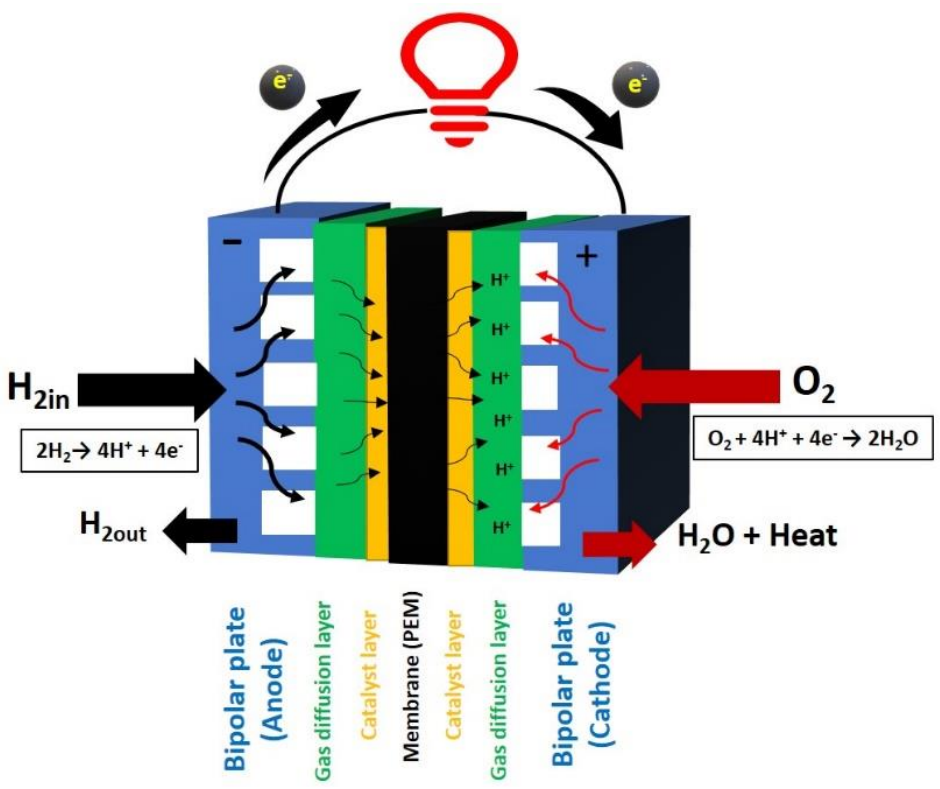

39 Fig 1: Components of a PEM fuel cell and schematic diagram of reactants' delivery path All three types of bipolar plates such as graphite, composite and metal plates are currently under

41 investigation for improved properties. However, according to recent publications more focus has 42 been given on composite as well as metal bipolar plate for fuel cell application. All of them has 
43 advantages and disadvantages and researchers put their best efforts for decades to bring out the

44 spectrum of new materials and solutions to the existing problems. To this end, our research

45 covered the effect of advanced carbon composites on the key properties of bipolar plates,

46 especially electrical and mechanical attributes. From the history of fuel cell, it is noted that the

47 specification for Bipolar plate is driven by DOE target, which is often used by industry as the

48 gold standard. From the DOE target chart, the main criteria for bipolar plate are cost, weight,

49 corrosion tendency, electrical conductivity, $\mathrm{H}_{2}$ permeation, areal specific resistance (interfacial

50 contact resistance) and flexural strength [17]. For the year 2020, DOE reduced the target criteria

51 for flexural strength compared to their 2015 target to strike a balance among the cost, electrical

52 conductivity and mechanical strength; the electrical conductivity is more of a desired criteria in

532020 and more important especially for composite bipolar plate as they have low electrical

54 conductivity issue due to presence of insulating resin matrix. (Table S1 in the supporting

55 document summarizes the merits and demits of different BPP)

56 Graphite was once the mainstream BPP material, but due to its bulk weight and volume,

57 brittleness and expensive machining process the focus has shifted to composite and metal bipolar

58 plates. Graphite shows many advantages such as low contact resistance, high corrosion resistance

59 and good electrical conductivity. The graphite BPP has poor mechanical strength and more

60 porous structure due to their particle properties which increases $\mathrm{H}_{2}$ permeability. Additionally,

61 the fabrication of channels becomes expensive, time consuming and barrier to mass production

62 because a computer numerical control machine is required [34-36]. Metal BPP is a potential

63 material due to its high electrical and thermal conductivity and good mechanical strength.

64 However, they are susceptible to corrosion and decomposition at fuel cell's harsh environment at

$65 \mathrm{pH} 2-4$ and humid operating condition of $80^{\circ} \mathrm{C}[6-10,37,38]$. Their greatest limitations are the 
corrosion prone nature, hydrophilicity and high interfacial contact resistance (ICR) which can

67 cause low power output and reduced efficiency of the cell; the membrane electrode assembly

68 (MEA) may be affected, the expensive Pt catalyst can be damaged, and the evolved corrosion

69 layer can increase the overall electrical resistance of the cell. Hence, the theoretical advantage

70 values can be nullified with the long-term operation of the fuel cell system.

71 Polymer composite bipolar plates come into play to resolve these fundamental problems and

72 show greater advantages in good pore tightening, improved mechanical strength, low contact

73 resistance, eradication of machining problem and above all excellent corrosion resistance.

74 However, they have low electrical conductivity issue due to non-conductive matrix and

75 increasing electrical conductivity needs higher filler content which by default reduces the

76 mechanical strength due to the brittle nature of the fillers [39,40]. This is a long-time ongoing

77 objective of the research to achieve a maximum balance between the electrical conductivity and

78 mechanical strength to provide a high-performance alternative of bipolar plate. Our research is

79 following this trend to provide an optimized options which show both high electrical and

80 mechanical properties well above the DOE target. (The specific comparisons are given in table

81 S2 in the supporting document).

82 For electrochemical comparison, the main criteria are corrosion resistance and interface contact

83 resistance which are two key factors for performance evaluation. The metal bipolar plates by

84 nature lack in both these factors as they are very susceptible to generation of undesirable oxide

85 layers, hence they cannot compete for higher life expectancy required by medium to heavy duty

86 operations. From chemical stability analysis it was found that SS304 plate has redox peak at -0.2

$87 \mathrm{~V}$ compared to graphite plate's $1.6 \mathrm{~V}$ [41]. This is an indication that the oxidation is predominant

88 over the reduction and hence the corrosion can spontaneously occur for metal plates. Even with 
different coating, the value comes close to $0-0.1 \mathrm{~V}$ [42] which is not sufficient to prevent

90 corrosion. For interfacial contact resistance, a very high value of $239 \mathrm{~m} \Omega \mathrm{cm}^{2}$ was observed for

91 SS316 metal bipolar plate which is much higher than the DOE target $\left(<10 \mathrm{~m} \Omega \mathrm{cm}^{2}\right)$ and is a

92 concern because $2-5 \%$ power loss can occur in PEMFC stack with an increase of $25 \mathrm{~m} \Omega \mathrm{cm}^{2}$

$93[43,44]$. Even with the coating materials, ICR for most of the metal bipolar plates values exceed

$9410 \mathrm{~m} \Omega \mathrm{cm} 2$ [45]. On the other hand, most of the composite plates show ICR values $<10 \mathrm{~m} \Omega \mathrm{cm} 2$.

95 For example, Taherian et al 2011 [46] and Cho et al 2004 [47] achieved ca. $9 \mathrm{~m} \Omega \mathrm{cm}^{2}$ and 7.42

$96 \mathrm{~m} \Omega \mathrm{cm}^{2}$ for composite bipolar plates which is within the DOE range. Due to the complex nature

97 of multi-component design of composite plates, the results can vary between different filler-

98 polymer pairs [11]. Nonetheless, very few literature on composite bipolar plate has undergone

99 electrochemical tests due to their non-corrosive nature. Herein, two common corrosion resistant

100 materials - carbon and epoxy are utilized which are well known for their chemical stability and

101 non-corrosive nature. This is more confirmed from no-metal presence in EDX analysis as shown

102 in fig 4b. An interesting option and potential future research can be using metal bipolar plate in

103 the anode side only where the corrosion potential is less predominant. In essence, BPP can be

104 fabricated with various materials and the commercialization of both composite and metal bipolar

105 plates are underway to facilitate different requirements depending on the industry. Therefore,

106 they are not really comparable rather parallelly moving forward and trade-offs between different

107 properties must be critically assessed to achieve a good balance between processibility and high

108 performances. Our main goal is to provide the scientific insight behind choosing different

109 functional and nano-structured advanced materials to facilitate fabrication of high-performance

110 bipolar plate composites. 
111 For important factors determinant of composite attributes, roughness and porosity are important

112 properties which can affect gas permeation, water absorption, electrical conductivity and

113 mechanical strength [12-16]. . Although there are a number of examples citing design and

114 fabrication of composite plates with diverse light weight carbon materials, rarely with epoxy

115 matrix they achieve a desirable functional attributes up to US DOE standard, such as electrical

116 conductivity $\left(>100{\left.\mathrm{~S} . \mathrm{cm}^{-1}\right)}^{-}\right.$and flexural strength $(>25 \mathrm{MPa})$. Some of the key scientific

117 challenges need to be addressed are the intrinsic properties of fillers and polymers as well as the

118 interfacial interaction. Moreover, to increase the overall usage of the fuel cell, it is important to

119 enhance the cost-effectiveness and performance of BPP; herein the cost-effectiveness is

120 maintained by utilizing minimum amount of nanofillers with maximum improvement of

121 composite electrical and mechanical attributes. The main desired properties other than electrical

122 conductivity and mechanical strength are chemical stability and gas impermeability which is

123 ensured here with stable raw materials and a high pressure fabrication process to minimize

124 porous structures within the composites. There is also a lack of investigation on graphitic

125 structure of various carbon-based energy materials which possesses adaptive functional

126 properties. To addresses the most pressing challenges of specific functional attributes of

127 composite plates, the structure of diverse carbonaceous materials and their multi-layered

128 graphitic structures have been investigated here to better understand the electron transfer through

129 composite structure designed for fuel cell bipolar plate and correlate their structure-property to

130 BPP functions. 


\section{EXPERIMENTAL}

132

133

134

135

136

137

138

139

\begin{tabular}{|c|c|c|c|c|c|c|}
\hline $\begin{array}{c}\text { Material } \\
\text { Name }\end{array}$ & Source & $\begin{array}{l}\text { Density } \\
\left(\mathrm{g} / \mathrm{cm}^{3}\right)\end{array}$ & $\begin{array}{c}\text { Mean particle } \\
\text { size }\end{array}$ & $\begin{array}{c}\text { Surface } \\
\text { Area } \\
\left(\mathrm{m}^{2} / \mathrm{g}\right)\end{array}$ & $\begin{array}{l}\text { Conductivity } \\
\left(\mathrm{S} . c m^{-1}\right)\end{array}$ & $\begin{array}{c}\text { Filler type } \\
\text { (Filler content } \\
\text { wt } \% \text { ) }\end{array}$ \\
\hline $\begin{array}{l}\text { Graphite } \\
4012 \text { (Gr) }\end{array}$ & $\begin{array}{l}\text { Asbury } \\
\text { carbon }\end{array}$ & 2.2 & $\bar{~} \sim 75 \mu \mathrm{m}$ & 1.27 & $\sim 30$ & Primary $(76 \%)$ \\
\hline $\begin{array}{l}\text { Graphite } \\
4056\end{array}$ & $\begin{array}{l}\text { Asbury } \\
\text { Carbon }\end{array}$ & 2.18 & $\sim 200 \mu \mathrm{m}$ & 1.27 & $\sim 30$ & Primary $(76 \%)$ \\
\hline $\begin{array}{l}\text { Carbon } \\
\text { Black } 5303 \\
\text { (CB) }\end{array}$ & $\begin{array}{l}\text { Asbury } \\
\text { Carbon }\end{array}$ & $\sim 0.1$ & $\sim 30 \mathrm{~nm}$ & 254 & $\sim 2.93$ & $\begin{array}{c}\text { Secondary }(1- \\
3 \%)\end{array}$ \\
\hline $\begin{array}{l}\text { Multiwall } \\
\text { carbon- } \\
\text { nanotube } \\
\text { (MWNT) }\end{array}$ & $\begin{array}{l}\text { Cheaptubes, } \\
\text { USA }\end{array}$ & $\sim 2.1$ & $\begin{array}{l}\sim 30 \mathrm{~nm} \text { (length } \\
\sim 20 \mu \mathrm{m})\end{array}$ & 110 & $>100$ & Secondary $(2 \%)$ \\
\hline $\begin{array}{l}\text { Carbon } \\
\text { Fiber }(\mathrm{CF})\end{array}$ & Zoltek PX35 & 1.81 & Dia. $\sim 7 \mu \mathrm{m}$ & 1.87 & $\sim 645$ & $\begin{array}{c}\text { Secondary (1- } \\
2 \%)\end{array}$ \\
\hline $\begin{array}{l}\text { Carbon Veil } \\
(\mathrm{CV})\end{array}$ & Fiber Glast & $\begin{array}{c}\text { Weight } \\
4.8-6.5 \\
\text { g/yd }\end{array}$ & $\begin{array}{l}\text { Thickness 50- } \\
100 \mu \mathrm{m}\end{array}$ & - & $\sim 2.85 \mathrm{~S} / \mathrm{cm}^{2}$ & Secondary (1pc) \\
\hline $\begin{array}{l}\text { Expandable } \\
\text { Graphite } \\
3558 \text { (ExG) }\end{array}$ & $\begin{array}{l}\text { Asbury } \\
\text { Carbon }\end{array}$ & 2.2 & $\sim 250 \mu \mathrm{m}$ & 23 & $\sim 30$ & Primary $(76 \%)$ \\
\hline
\end{tabular}
$12(\mathrm{Gr})$
aphite
rbon
ack 5303
bon-
bottiwall
bon
bon
bon Veil

\subsection{Methods:}

2.2.1 Composite fabrication process: In this research, direct mixing and compression molding technique was used as the main process to fabricate the composite samples. The general method 143 includes optimized mixing of carbonaceous materials and polymer matrix, fabricating composite 
144 through hot molding process (fig. 2) and finally, characterization for conductivity, mechanical

145 strength and morphological analysis for interface properties. In general, the carbon-based

146 materials were mixed in a mechanical mixer (Caframo RZR1) at 200-300 rpm at ambient

147 temperature. Primary fillers were placed first and the polymer resin and hardener or curing agent

148 (polyamine based) were added dropwise with continuous mixing, then the secondary fillers were

149 added intermittently at the end and mixing continued for more 15 minutes to ensure even

150 dispersion of fillers in the matrix. Nanofillers and CF contents are kept within threshold to

151 withhold the cost-effectiveness as well as high performance of the composites. For carbon veil, it

152 was used in the middle of layers of filler-matrix mixture as a pre-preg system. The mixture was

153 then compressed in the Carver hot press machine for $10-15$ minutes at $110-120^{\circ} \mathrm{C}$ and $55 \mathrm{MPa}$

154 (8000 psi). In case of expanded graphite (EG), it was processed from expandable graphite (ExG)

155 by heating up in muffler furnace at $950^{\circ} \mathrm{C}$ for 30 seconds

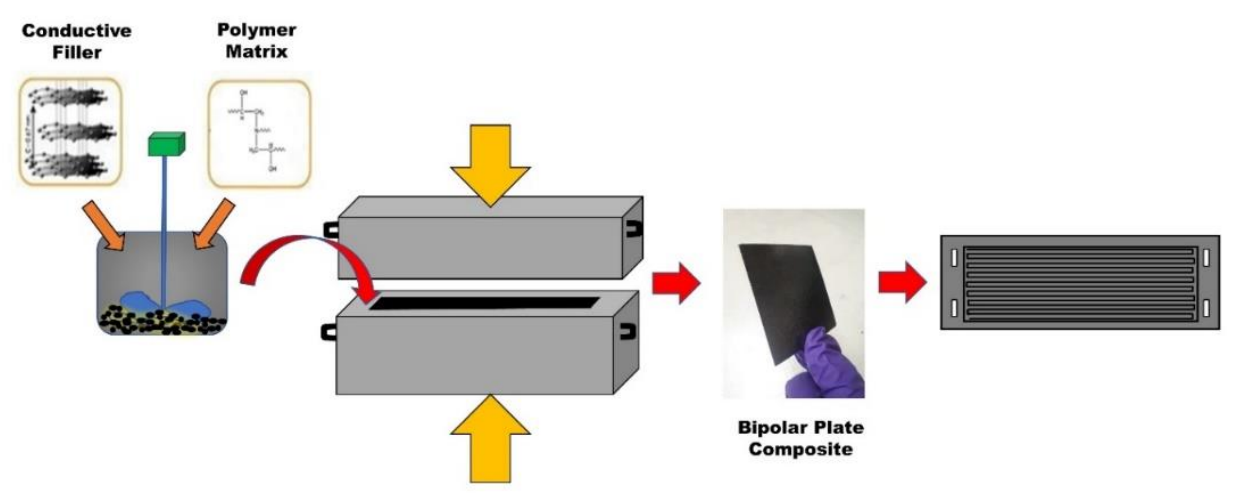

157 Fig 2: Compression molding process for fabrication of bipolar plates

2.3 Characterization:

159 The following machines and processes were used for characterization of the carbon polymer 160 composite (Details in the supporting document) 
172 XRD:
Conductivity:

Conductivity was measured by 4-point probe method using high-precision Keithley 2450 source meter and Everbeing 4-point probe station. Results were averaged from 3 samples and 5 points in each sample. Sample size was $75 \times 75 \times 1.1 \mathrm{~mm}$.

Flexural strength: Flexural strength was measured by 3-point bending test (ASTM D790-3) using Instron 3367. Support span length $25 \mathrm{~mm}$ and overhead speed was $1 \mathrm{~mm} / \mathrm{min}$

Micro CT scanning: X-ray Micro-computed 3D Tomography-SkyScan 1172

Contact angle: $\quad$ Contact angle machine OCA 15EC (sessile drop method with water )

Morphology: $\quad$ Scanning electron microscope (JSM-6610LV) and Energy Dispersive Spectroscopy (Oxford, 20 $\mathrm{mm}^{2}$ )

Philips PW $3710 \mathrm{CuK} \alpha$ radiation $(\lambda=0.15406 \mathrm{~nm})$ at $40 \mathrm{kV}$ and $30 \mathrm{~mA}$ with $0.02^{0}$ step size, $2.5 \mathrm{~s} / \mathrm{step}$ and $0.008^{0} \mathrm{~s}$ scanning rate.

\section{RESULTS AND DISCUSSIONS:}

Functional fillers play a more important role in determining the electrical conductivity of the carbon polymer composites than the polymer matrix. Herein we report the effect of graphitic carbon structure and their dispersion on BPC performance.

\subsection{Graphite and Graphitic structure:}

In case of the graphite-epoxy composite particles, Raman spectra showed how the lattice can be varied with the addition of different materials. For Graphite composite (fig. 3), the D peak, G peak and 2D peaks were observed at 1350,1580 and $2700 \mathrm{~cm}^{-1}$ respectively. For composites with expandable graphite $(\mathrm{ExG})$ and expanded graphite $(\mathrm{EG})$ these peaks were not much shifted 
184 as shown in fig. 4, however, peaks broadening in G peaks (6\% for Graphite-EG and 27\% for

185 ExG), and splitting in 2D peaks were observed which indicates the presence of defects and more 186 layered structure has been formed which induces more electrical conductivity in these

187 composites.

188

189

190

191

192

193

194

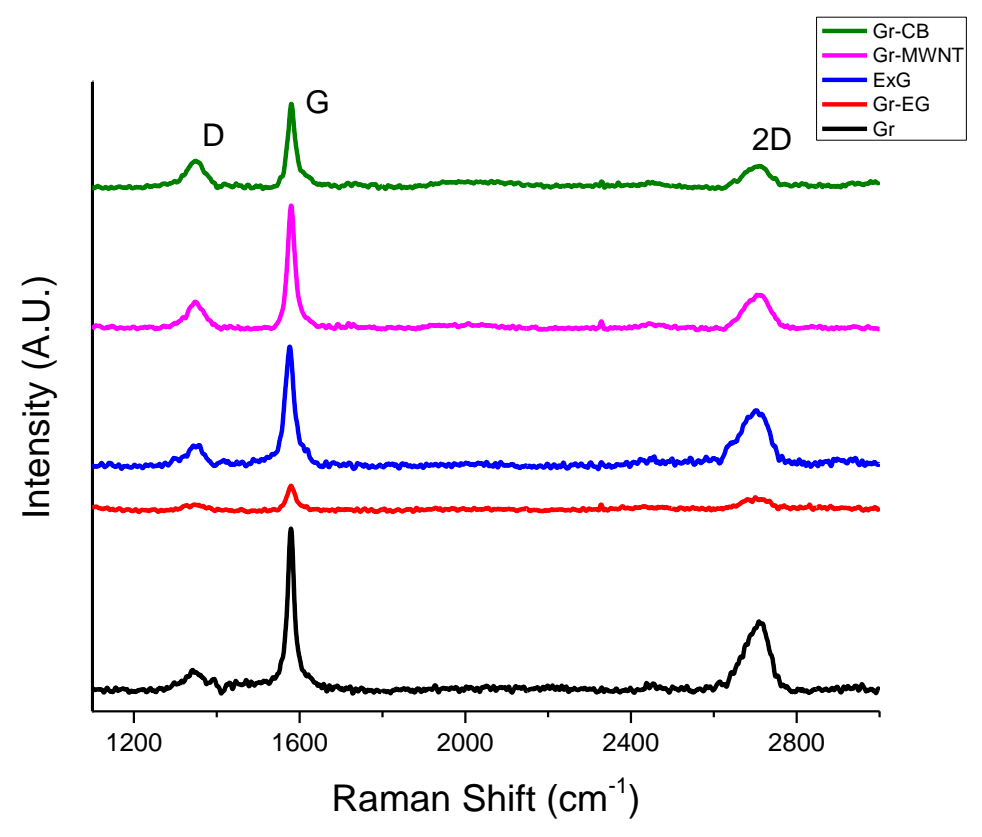

Fig 3: Comparison of Raman spectra of the composites with various carbon materials

For expanded graphite, $27 \%$ increase in $\mathrm{I}_{2 \mathrm{D}}$ and $\mathrm{I}_{\mathrm{G}}$ ratio signifies the layer expansion and presence of more graphene like structure (table 2). With introduction of MWNT and CB in the graphite-epoxy composite (fig 3), the broadened peaks were found with less intensity in graphitic bond (G peak) which indicates that the lattice is slightly distorted, and amorphous carbon became more dominant due to the more amorphous nature of these materials. This is evidenced from the increase and decrease in $\mathrm{I}_{\mathrm{D}} / \mathrm{I}_{\mathrm{G}}$ and $\mathrm{I}_{2 \mathrm{D}} / \mathrm{I}_{\mathrm{G}}$ ratio respectively (table 2 ). It is possible that these changes in the band intensity is due to the de-bundling of nano fillers by penetration of polymer chains during composite melt mixing [18]. The resulting composite expects to show higher conductivity due to higher amorphous carbon content. 
Table 2: Raman spectra data for different compositions of the composites

\begin{tabular}{lccccc}
\hline \hline Sample & D peak & G peak & 2D peak & $\mathbf{I}_{\mathbf{D}} / \mathbf{I}_{\mathbf{G}}$ & $\mathbf{I}_{\text {2D }} / \mathbf{I}_{\mathbf{G}}$ \\
\hline \hline Gr-CB & 1347 & 1582 & 2711 & 0.34 & 0.28 \\
Gr-MWNT & 1351 & 1578 & 2706 & 0.23 & 0.28 \\
ExG & 1351 & 1578 & 2700 & 0.2 & 0.48 \\
Gr-EG & 1353 & 1578 & 2701 & 0.3 & 0.56 \\
Gr & 1342 & 1582 & 2716 & 0.14 & 0.44 \\
\hline \hline
\end{tabular}

200

201

202

203

204

205

206

207

208

209

210

211

212

213

214

It is well known that in graphitic hexagonal lattice structure with layered planes, the interatomic distance is $1.42 \AA$ and interlayer distance is $3.354 \AA$ (fig $4 \mathrm{a})$. One out-of-plane p-bond in each carbon atom contains delocalized electron which is responsible for high thermal and electrical conductivity. In a shear processed graphite as above intercalated and/or exfoliated layers are held adjacently by weak Van der Waals force and hence graphite layers can slip past one another leading to demonstrate lubricating behaviour and softness [19].

a)

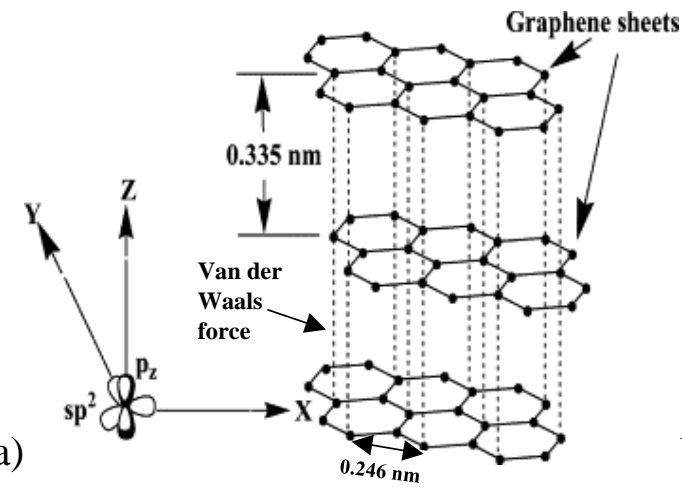

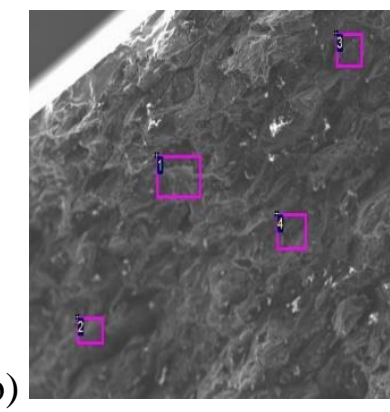

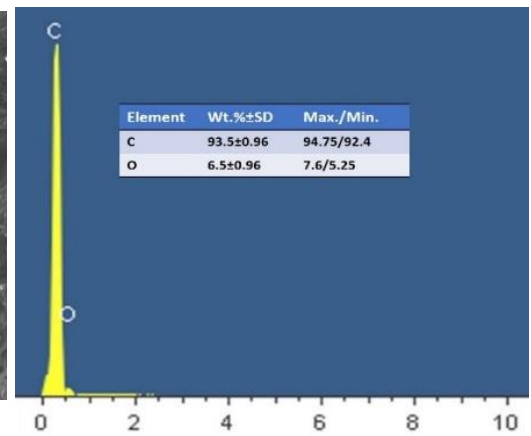

Fig 4: a) Graphitic structure [20], b) SEM/EDX analysis of graphite-epoxy composite

From the EDX analysis, the presence of carbon and oxygen and predominance of carbon

molecules (ca. 15:1) are confirmed in the composition as shown in fig. 4b. In order to obtain

deeper insight, graphitic crystal lattice along with the excitation states are determined by Raman

spectroscopy which can be related to improvement of electrical conductivity (table 2). From the

Raman spectroscopy data, the conformational changes were determined within the lattice of the

graphite in the composite fabricated with epoxy resin and various carbonaceous materials which

can be best described by the Brillouin zone (BZ) and phonon dispersion from fig. S2 (in the 
215 supporting document) and table 2 . The Raman spectra mostly show the $\mathrm{sp}^{2}$ vibration as excitation that mainly resonates with the $\pi$ states of the molecule and this is true even for highly

$217 \mathrm{sp}^{3}$ amorphous carbon. This is a well- established fact that the G peak in the spectra is caused by

218 the stretching of $\mathrm{sp}^{2}$ atoms in both rings and chains whereas the $\mathrm{D}$ peak by breathing modes of $219 \mathrm{sp}^{2}$ atoms only in rings. The difference between $\mathrm{D}$ and $2 \mathrm{D}$ is that $2 \mathrm{D}$ band involves two TO

220 (Transverse and Optical) phonon near the K point and D band originates from one TO phonon 221 and one defect [21]. These are all caused by the Kohn anomalies for $\Gamma-\mathrm{E}_{2 \mathrm{~g}}$ and $\mathrm{K}-\mathrm{A}^{\prime}{ }_{1}$. However,

222 for carbon nanotubes, stronger Kohn anomalies is present due to their reduced dimensionality.

223 This gives phonon softening [22] and their presence make the Raman spectra different for the

224 composites which can be observed from reduced $\mathrm{ID}_{\mathrm{D}} \mathrm{I}_{\mathrm{G}}$ ratio in table 2.

225

226

227

228

229

230

231

232

\subsection{Different sized Graphite Particles:}

In general, functional fillers have more influence on the conductivity than the matrix. The conductivity can be improved by tuning fillers effectively. For example, if two fillers of different sizes are used, there can be less void space in between the round particles. As a result, the conductive path is formed easily, and the composite becomes more conductive. This can be explained from the equation 1 [23]

$$
\mathrm{R}_{\mathrm{c}}=\frac{1}{2} \rho\left(\frac{2}{3} \frac{E}{1-v^{2}}\right)^{1 / 3} \mathrm{~F}^{-1 / 3} \mathrm{r}^{-1 / 3}
$$

Where, $R_{c}$ is the constriction resistance, $\rho$ is the bulk resistivity, $\mathrm{E}$ is the young's modulus, $\mathrm{F}$ is the exerted force between the particles, $v$ is the poisson's ratio and $\mathrm{r}$ is the protrusion radius. From the equation 1, it can be found that the increase in protrusion radius $\mathrm{r}$ as well as force $\mathrm{F}$ can decrease the contact resistance. From our results, it has been found that using synthetic graphite (SG) with bi-modal size selection show better result than one-size filler (fig 5a) for both conductivity and flexural strength. Also, for composites containing a single size filler, fillers with bigger particles 
239 when used in the same amount, show better conductivity due to the bigger protrusion radius (fig 240 5a). From our experiments, we found about $18 \%$ increase in conductivity for graphite with larger 241 particle size. Two variables, namely aspect ratio and difference in diameters in this case contributes 242 to increasing protrusion radius as shown from equation 1. As a result, the average distance between 243 the filler particles decreases facilitating the electron hopping process (fig 5c) which can be also 244 found in the one-way ANOVA result as the compositions are significantly different $(\mathrm{p}<0.05)$. 245 Hence, the increase in aspect ratio of carbon fillers increases conductivity at any particular loading $246[16,24,25]$. We also found that $56 \%$ of $200 \mu \mathrm{m}$ filler and $20 \%$ of $75 \mu \mathrm{m}$ filler combination showed 247 the best conductivity of $217 \mathrm{~S} / \mathrm{cm}$ and flexural strength of $38 \mathrm{MPa}$ (fig 5a). In most cases, flexural 248 strength somewhat decreased with increasing electrical conductivity. This is due to the fact that 249 the determinants for electrical conductivity and mechanical strength are different in nature. A more 250 continuous electron flow path formation due to bi-modal distribution of carbon particles 251 dominantly reflected in higher conductivity as schematically shown fig. 5c; however, brittleness 252 of the carbonaceous fillers and weaker interface between carbon particles and resin led to lower 253 ductility of the composite.
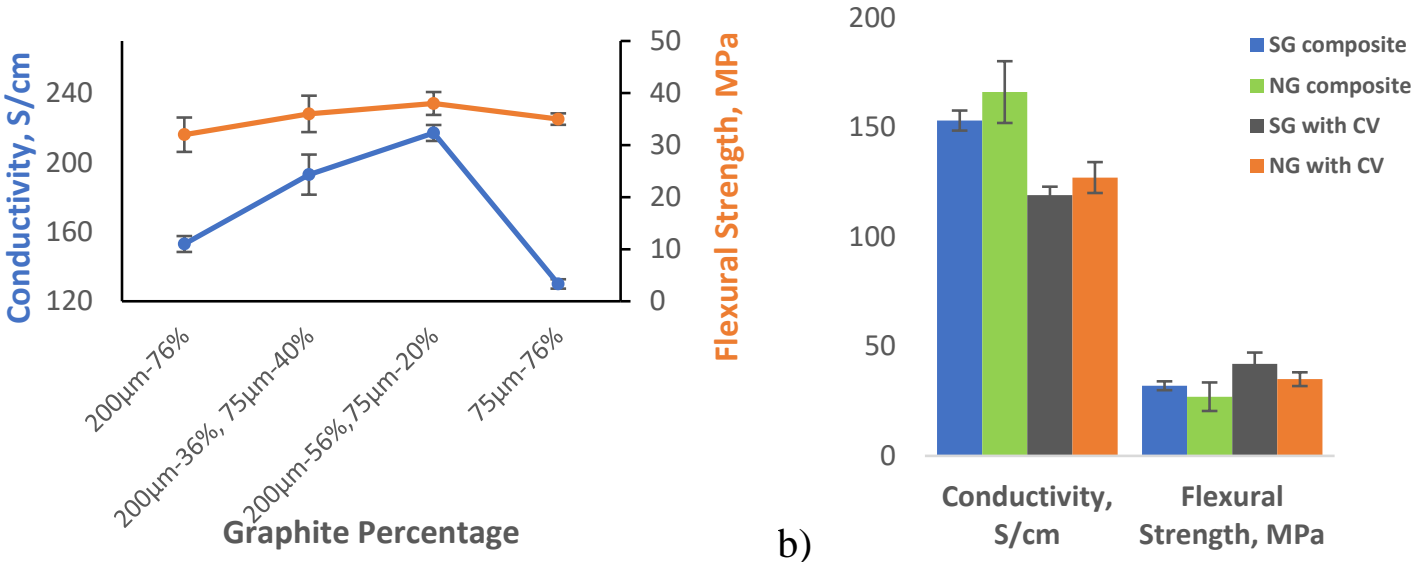
c)

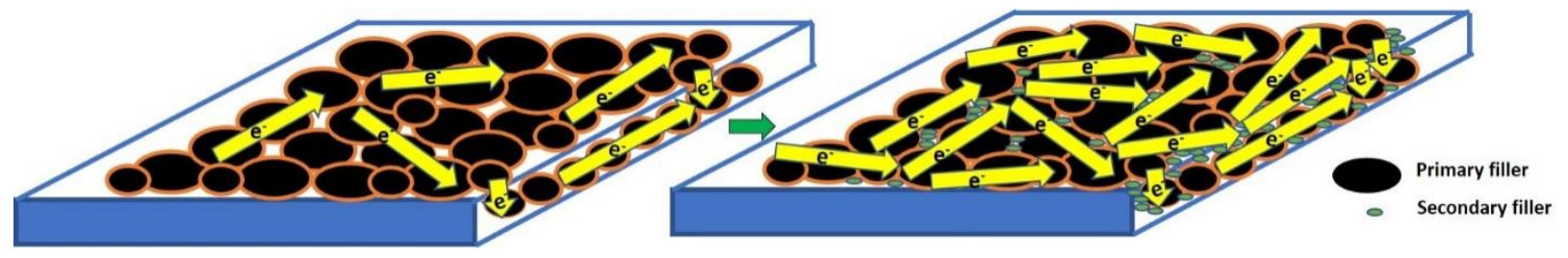

Fig 5: a) Effects of different composition with graphite of different particle sizes $\left(\mathrm{p}=4.9 \times 10^{-6}\right)$ fillers with primary filler and b) Comparison between synthetic and natural graphite filler without and with Carbon veil $(\mathrm{p}=0.0018), \mathrm{c})$ Scheme of increased conductive network due to addition of different size or secondary fillers Experiments were also carried out with the natural flake graphite (NG) and compared with the results of synthetic graphite (SG). NG based composite has $8 \%$ more conductivity than SG based composite which is shown by the one-way ANOVA result as they are significantly different $(\mathrm{p}<0.05)$, however, flexural strength remained relatively indifferent (fig $5 \mathrm{~b}$ ). This may be because the difference in surface energies between filler and polymer matrix is greater for NG. Also, for natural graphite, its structural morphology differs between different sizes and also depends on the source of the graphite, their variations in production process and impurities

267 present [26].

268

269

\subsection{Effects of carbon nanomaterials:}

Carbon black (CB) is a preferable nanofiller due to its lower cost and larger surface area. It also contains functional groups such as carboxyl, phenols, quinones and lactones that affect the blending with polymer matrix as well as the improved properties for the composite [10]. The main properties of carbon black that determine the electrical conductivity of the composite are particle size, structure, and degree of graphitization [27-30]. Multiwalled carbon nanotubes (MWNT) are the layers of graphene in rolled forms. They are more cost-effective than singlewall nanotubes (SWNT) and have high potential to enhance electrical conductivity due to their high aspect ratio [31]. From the experiments, both nano-sized CB and MWNT improved the electrical and mechanical performance of the composite which can be observed from the 
278 ANOVA result as they are significantly different $(\mathrm{p}<0.05)$. For $\mathrm{CB}$, high electrical conductivity

279 of $221 \mathrm{~S} / \mathrm{cm}$ was observed when used with expandable graphite and high flexural strength of 52

$280 \mathrm{MPa}$ was achieved in a hybrid system with carbon fiber (fig 6a). For MWNT, the highest value

281 of electrical conductivity of $201 \mathrm{~S} / \mathrm{cm}$ was achieved with ExG and flexural strength of $50 \mathrm{MPa}$

282 with CF in the hybrid system (fig 6b). However, CB shows better electrical conductivity in the

283 non-hybrid system, whereas MWNT shows better performance when used along with carbon

284 fiber or carbon veil. This may be because carbon black has more surface area than MWNT (254

$285 \mathrm{~m}^{2} / \mathrm{g}$ compared to $\left.110 \mathrm{~m}^{2} / \mathrm{g}\right)$. On the other hand, MWNT has less surface energy difference with 286 carbon fiber, $5 \mathrm{~mJ} / \mathrm{m}^{2}$ compare to $14 \mathrm{~mJ} / \mathrm{m}^{2}$ for $\mathrm{CB}$.

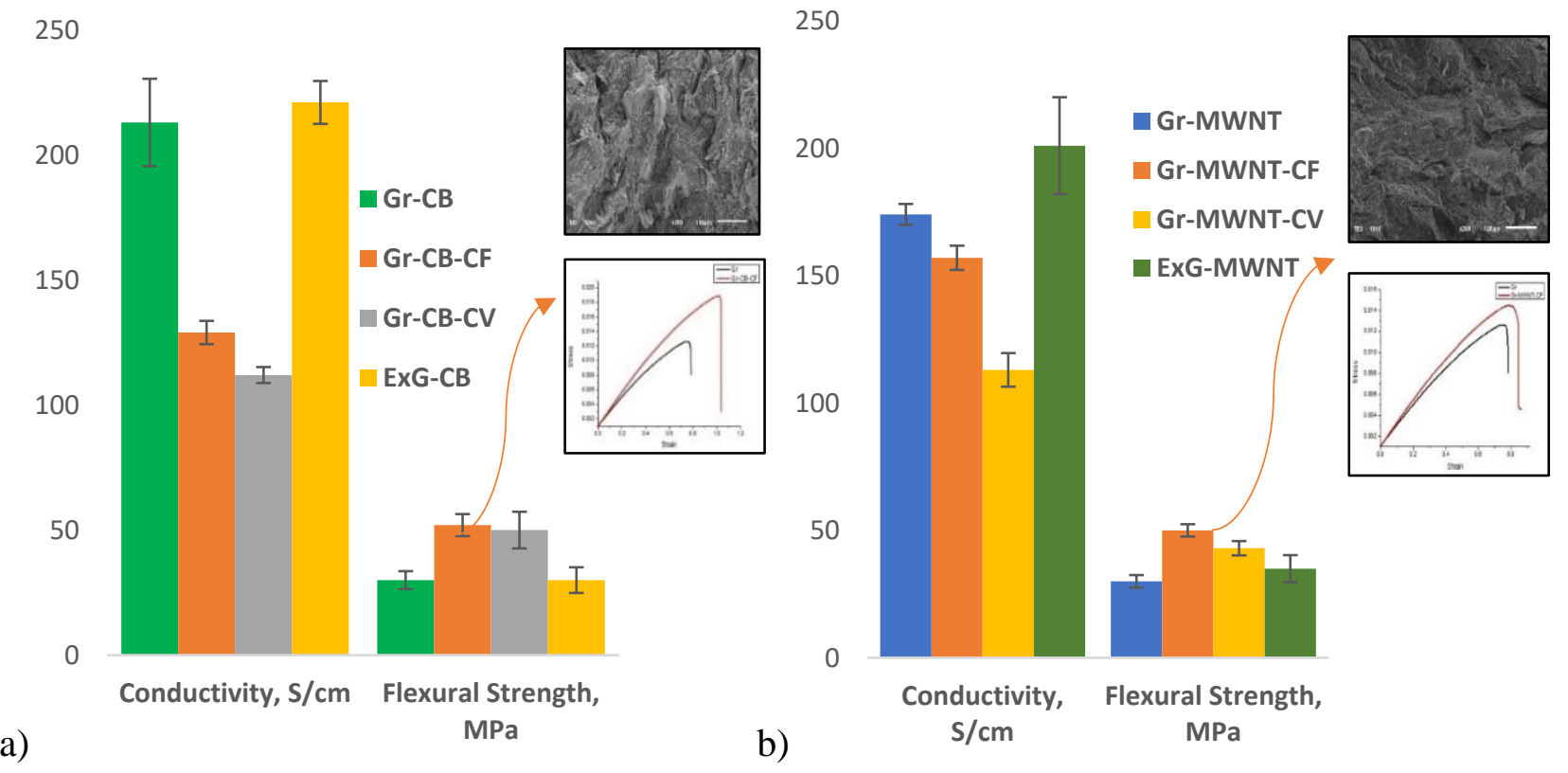

288 Fig 6: Electrical conductivity and flexural strength for different compositions a) for carbon black $289(\mathrm{p}=0.00001) \mathrm{b})$ for multi-walled nanotube $(\mathrm{p}=0.0002)$

290 It can be inferred that both nano particles and fibrous fillers should be used below the threshold 291 due to wettability issue. Agglomeration can occur if the wettability of multiple components is not 292 optimized. From SEM pictures, it was found that CB particles are not as visible in the through 293 plane surface and they are more dispersed in the in-plane direction (fig. S3c in the supporting 
294 document); proper dispersion with high shear is required to get desired results as they tend to

295 agglomerate when mixed at low shear such as an rpm below 100 (fig. S3b). Use of sonication

296 and higher rpm ( 400 rpm) improved the dispersion (fig. S3a); Nonetheless, an excessive rpm

297 can cause damage to graphite particles and layers which affects the composite properties

298 adversely.

299 3.4 Effects of expanded and expandable graphite/GIC:

300 Expanded graphite (EG) is an important modification of graphite layers to facilitate

301 functionalization for electrical and mechanical properties. It comprises of 100-200 times

302 expansion of the graphite layers initiated from graphite intercalation compounds (GIC) or

303 expandable graphite $(\mathrm{ExG})$, by the decomposition of intercalants present inside the graphite

304 layers. ExG is also a potential material to increase the conductivity of the composite with low

305 mass density at room temperature. It can absorb guest atoms between the graphene layers by

306 forming ionic bonds which increase the conductivity of the graphite by adding electrons to its

307 conduction band or holes to the valence band. Graphite is modestly conductive with a value of

308 around $2 \times 10^{-4}$ carriers/atom $\left(2 \times 10^{19} / \mathrm{cm}^{3}\right)$ [32]. The intercalation process provides injection of

309 carriers from the intercalant layer, electrons for donors and holes for acceptors to the graphite

310 layer and create a high mobile system. Hence, the graphite layer becomes charged and the

311 released charge gives rise to the charge density in the graphite layers. McRae et al [33]

312 concluded that the intercalant in the graphite layer stays in an ordered array and not as a

313 statistical distribution. From the results for conductivity and flexural strength, it was observed

314 that both expandable graphite and expanded graphite increase conductivity (fig. 7) up to 221

$315 \mathrm{~S} / \mathrm{cm}$, but reduce the flexural strength up to $27 \mathrm{MPa}$ as they have more layered structure with

316 increased distance between the layers that lessens the bonding and wettability. Also,

317 delamination may occur as found from the SEM pictures (fig 8). 


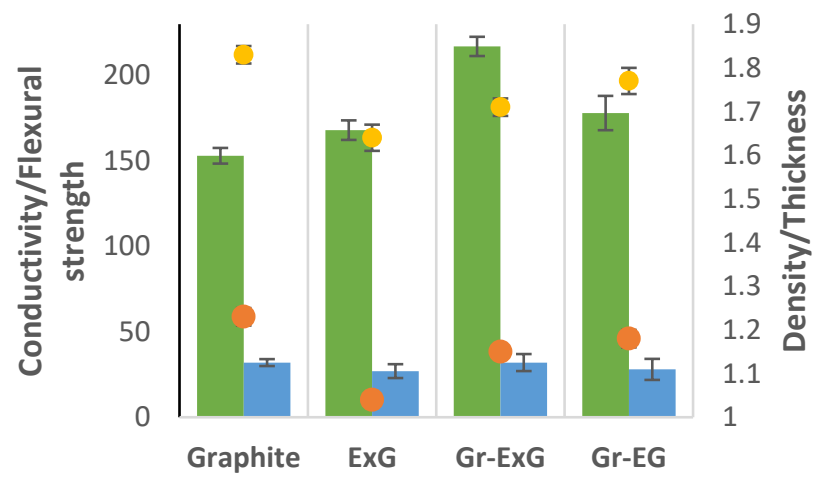

- Conductivity, $\mathrm{S} / \mathrm{cm}$

- Flexural Strength, MPa

- Density, g/cc

Avg Thickness, mm

319 Fig 7: Comparison of conductivity and flexural strength for graphite, expandable graphite and 320 expanded graphite on the basis of density

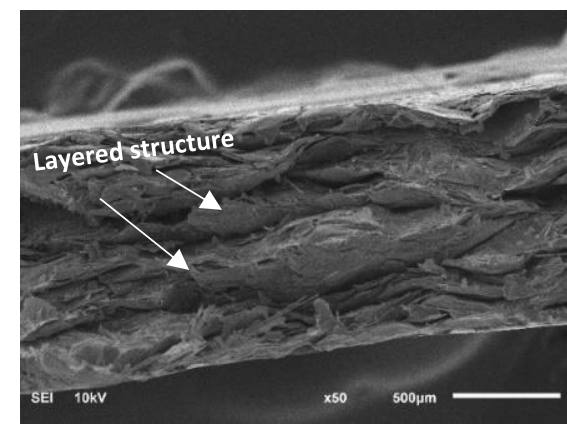

b)

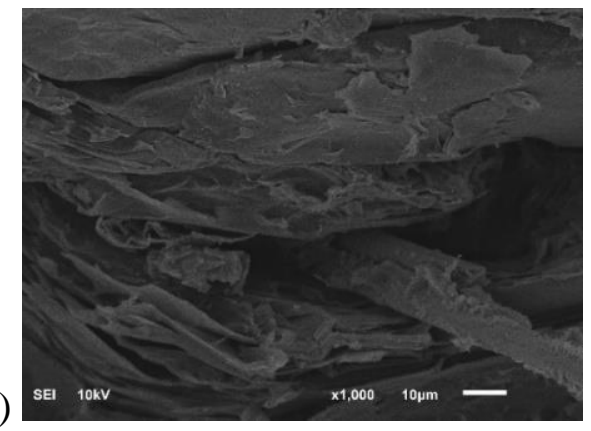

322 Fig 8: SEM images of the fractured surface- a) layers from graphite intercalated compounds b)

323 carbon fiber within the GIC layer

324 From the SEM pictures (fig. 8), it was also observed that with intercalated graphite there is more 325 denser and visible layers of graphite, hence the density is reduced about $10 \%$ from $1.83 \mathrm{~g} / \mathrm{cm}^{3}$ to $3261.64 \mathrm{~g} / \mathrm{cm}^{3}$ (measure as per ASTM D792) as shown in fig. 7. The average thickness is also 327 reduced by $18 \%$ from $1.23 \mathrm{~mm}$ to $1.04 \mathrm{~mm}$ when the process parameters were kept same during 328 fabrication (fig. 7). Above properties enable the fabrication of a light-weight high performance 329 composite for fuel cell application which is important for US DOE's cost vs performance target. 330 Raman spectroscopy provides a non-destructive and fast characterization of nanoparticles and 331 their composites with maximum structural and electronic information which can be verified by 
332 XRD. For graphene, in general, the 2D peak intensity increases significantly than the graphite 333 and also in case of lesser number of graphene layers present, the $\mathrm{G}$ peak decreases.

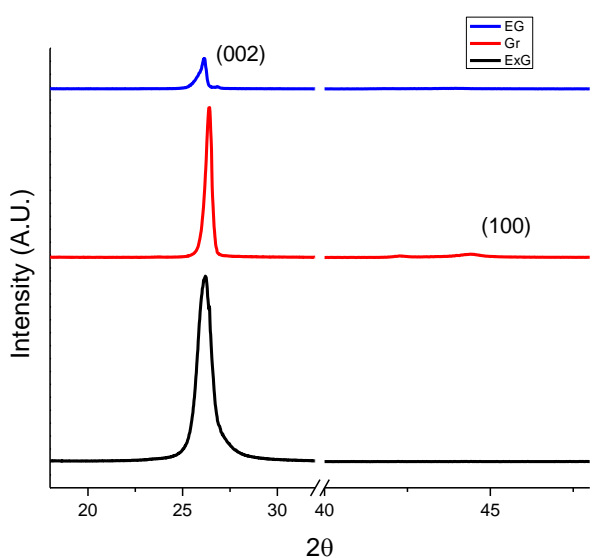

a)

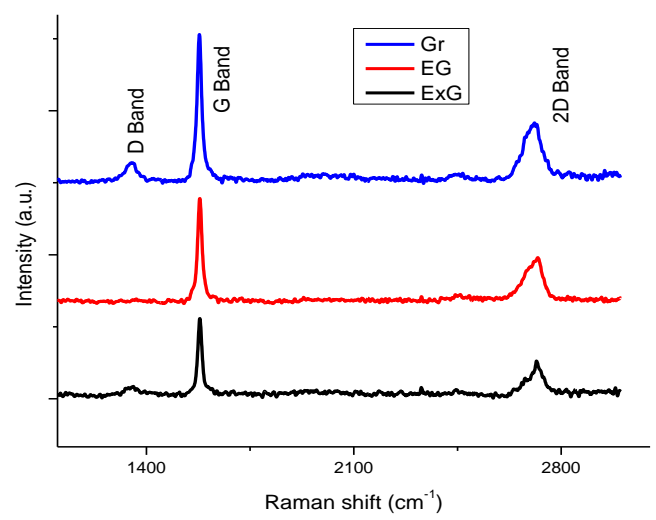

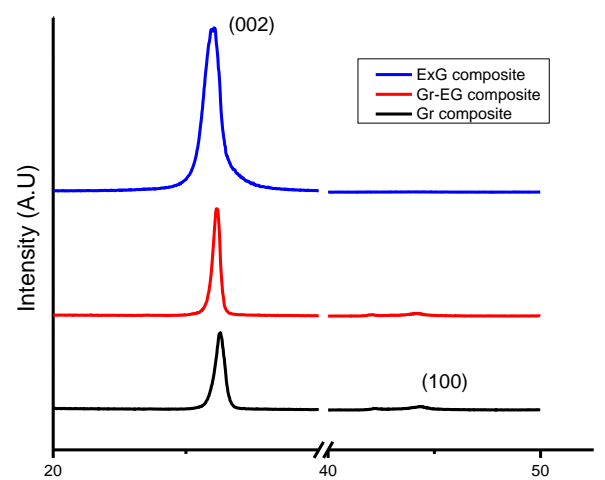

b)
334

335

c)

336 Fig 9: Difference between Graphite, expanded graphite and expandable graphite from a) XRD of 337 materials, b) XRD of composites and c) Raman spectroscopy of graphitic materials

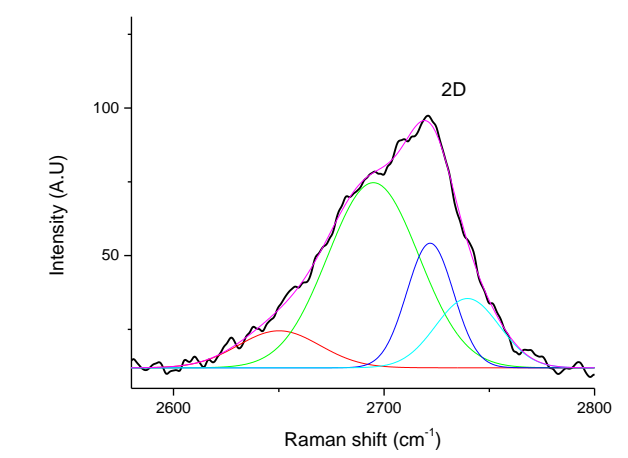

\section{8 a)}

b)

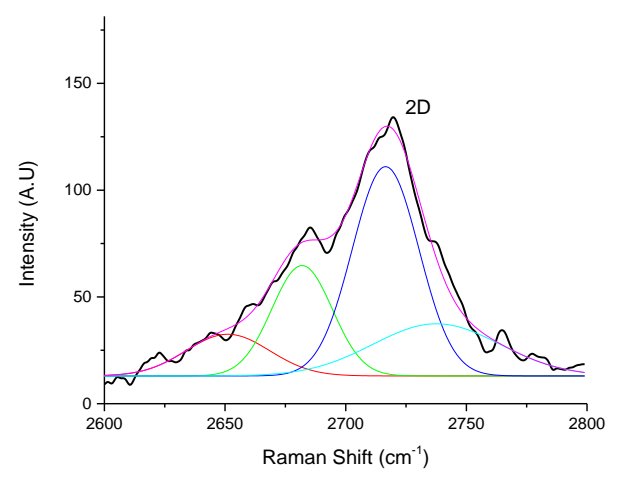


339 Fig 10: Deconvoluted 2D peak analysis for a) expanded graphite and b) expandable graphite 340 Reduction in both (002) and (100) plane from fig. 9a and decreased intensity of D band peak as 341 well as $\sim 10 \%$ increase in $(2 \mathrm{D} / \mathrm{G})$ ratio in fig. $9 \mathrm{~b}$ and table 3 indicate reduction of defects and 342 exfoliation of layers in the graphite lattice structure. After deconvolution, four sub-peaks were 343 found at 2649, 2694, 2722 and 2739 for EG and 2651, 2682, 2716 and 2737 for ExG respectively 344 (fig. 10) which indicates the change from graphite to graphene like layered structure contributing 345 towards enhancement of electrical conductivity. From Table 4, it can be inferred that there is an 346 increase between the spacing for EG and ExG compared to graphite as the d-spacing increases; it 347 is true for both these carbon materials and their composites. There were also changes in 348 crystallite sizes in the atoms, 55\% and 17\% reduction for ExG and EG respectively (table 4) 349 which indicates change in crystallinity due to breakage of layers. From the XRD and Raman 350 spectroscopy analysis (fig $9 \&$ table 3,4 ), we concluded that the expanded graphite shows more 351 graphene like structure than graphite and expandable graphite, as the distance between layers is 352 expanded. However, in case of composite structure, the influence of graphite is more prominent 353 due to low EG content (2-3\%) as there is difference of Raman and XRD analysis between the 354 carbon materials and their composites which is revealed for the first time in our research.

355 Table 3: Raman peak analysis

\begin{tabular}{lccccc}
\hline \hline Sample & D & 2D & G & $\mathbf{I}_{\mathbf{D}} / \mathbf{I}_{\mathbf{G}}$ & $\mathbf{I}_{\mathbf{2 D}} / \mathbf{I}_{\mathbf{G}}$ \\
\hline \hline Gr & 1351 & 2713 & 1581 & 0.14 & 0.41 \\
ExG & 1342 & 2716 & 1580 & 0.15 & 0.46 \\
EG & - & 2718 & 1578 & - & 0.45 \\
\hline \hline
\end{tabular}

357 Table 4: D-spacing and Crystallite sizes of different materials \& composites from XRD

\begin{tabular}{lccc}
\hline \hline Sample & $\mathbf{2 \theta ( 0 0 2 )}$ & $\begin{array}{c}\text { d-spacing, } \\
\text { nm }\end{array}$ & $\begin{array}{c}\text { Crystallite size, } \\
\mathbf{n m}\end{array}$ \\
\hline \hline Graphite & 26.37 & 3.37 & 19.35 \\
ExG & 26.16 & 3.40 & 8.72
\end{tabular}




\begin{tabular}{llll} 
EG & 26.05 & 3.42 & 16.12 \\
Gr Comp. & 26.27 & 3.39 & 18.04 \\
Gr-EG Comp. & 26.14 & 3.40 & 23.98 \\
ExG Compo. & 25.97 & 3.42 & 10.73 \\
\hline \hline
\end{tabular}

\section{$358 \quad 3.5$ Pore effects on conductivity:}

359 The presence of less porous structure in the BPP composite is an important criteria for target

360 application of bipolar plates. This is important mainly because the porous structure can lead to

$361 \mathrm{H}_{2}$ gas permeability and thus reduce the efficiency of the fuel cell. To understand the pore effects

362 on the performance of carbon polymer composite, the pore areas were calculated for various

363 composition and a relation between the conductivity and the porous structure of the composites

364 were investigated by a non-destructive test with x-ray Micro CT. There can be two kinds of

365 micro-structures observed inside the composite in fig 11a, the dark grey structures indicate resin

366 matrix whereas the bright white dots indicate pores or air voids in the samples. The analysis by

367 3D images from x-ray Micro CT scan showed that the composite with less porous structures

368 have better conductive properties. For example, comparing between the $3 \mathrm{D}$ images of fig $11 \mathrm{~b}, \mathrm{~d}, \mathrm{f}$

369 and $11 \mathrm{c}, \mathrm{e}, \mathrm{g}$, the later has bigger and denser pores (white dots) which is reflected in their

370 conductivity values of $217 \mathrm{~S} / \mathrm{cm}$ and $135 \mathrm{~S} / \mathrm{cm}$ respectively. In our study, $10 \times 15 \times 1.1 \mathrm{~mm}$

371 samples were scanned by SkyScan 1172 with pixel size of $8-11 \mu \mathrm{m}$. The projected images were

372 acquired at 0.7 degree rotation increment over $360^{\circ}$ and with an exposure time of $600 \mathrm{~ms}$. After

373 reconstruction and analyzing different composites by NRecon and imagej softwares and also

374 from measured contact angles, we concluded that the porous structure is related to the increase or

375 reduction of overall conductivity of the composite. 

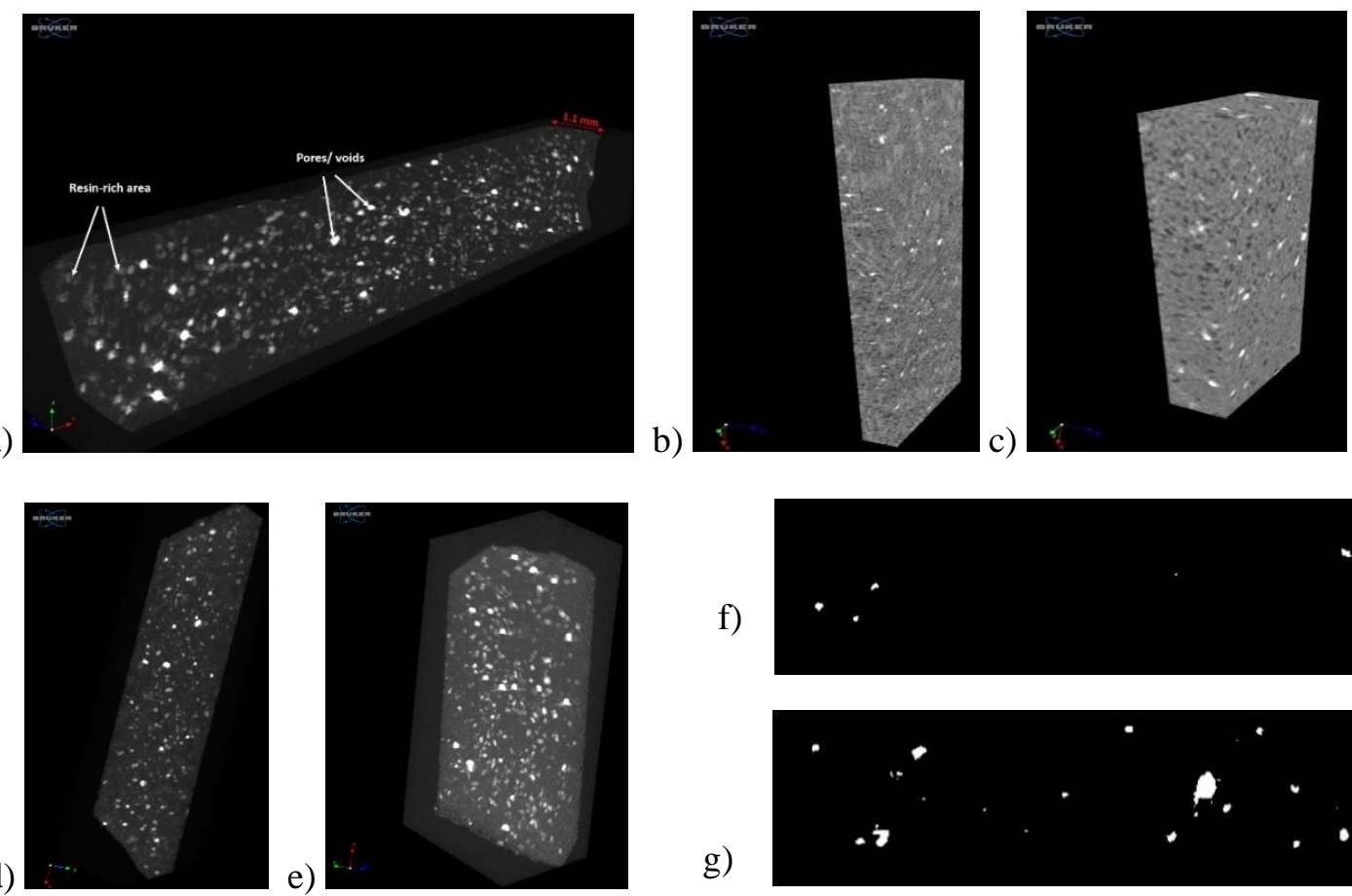

f)

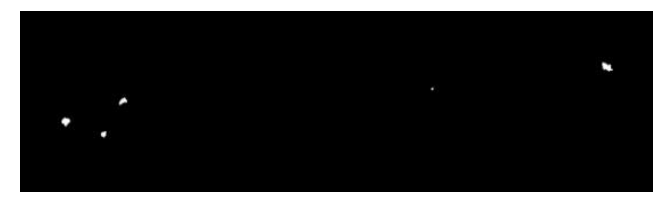

g)

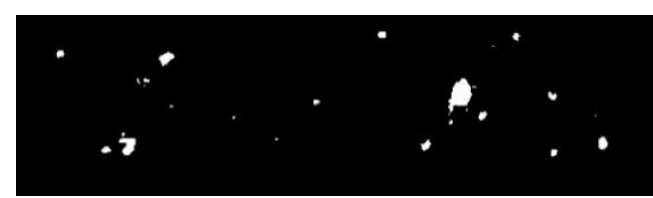

378 Fig 11: 3D images from X-ray $\mu$ Tomography showing pores in the internal structure of the

379 composite a-general sample showing pores and resin matrix, b,d \& f- after reconstruction

380 From the table 5, it can be inferred that the less pore area and higher contact angle is

381 incorporated to higher conductivity because of the established continuous conductive network

382 enhancing electron transfer. For example, the introduction of carbon fiber or carbon veil

383 increases pore area and decrease the hydrophobicity as shown in table 5. Similarly, the use of

384 multiple secondary fillers as well as increase of resin matrix increases percentage of porous

385 structure due to poor wettability. The pore area was calculated taking average of 50 layers

386 reconstructed from X-ray $\mu$ Tomography and contact angle was measured by the sessile drop

387 method. Further investigation is required to establish a relation between porosity and other

388 composite properties. Anisotropically distributed advanced functional carbonaceous materials

389 are difficult to analyze due to their complex nature of interaction in the composite, but the non-

390 destructive techniques used in this paper can mostly capture their functional characteristics in

391 terms of the desired properties of carbon polymer composite. Future research may include the 
392 enhancement of mechanical properties by introducing novel materials such as continuous and

393 functional fibrous materials without increasing the porous structure within the composite.

394 Table 5: Comparison between different composites showing the influence of porous structure on

395 the conductivity of the composite

\begin{tabular}{crcc}
\hline \hline Materials $^{*}$ & $\begin{array}{c}\text { Conductivity, } \\
\text { S/cm } \pm \text { SD }\end{array}$ & $\begin{array}{c}\text { Pore area\% } \\
\text { (NPA }^{* *} \pm \text { SD) }\end{array}$ & $\begin{array}{c}\text { Contact angle, } \\
\text { degree } \pm \text { SD }\end{array}$ \\
\hline \hline Gr56-ExG20 & $217 \pm 5.6$ & $1.3(98.7 \pm 0.6)$ & $82.1 \pm 1.0$ \\
Gr76 & $153 \pm 4.6$ & $2.1(97.9 \pm 0.6)$ & $80.3 \pm 3.8$ \\
Gr74-CF2 & $135 \pm 4.2$ & $2.3(97.7 \pm 0.8)$ & $75.9 \pm 1.5$ \\
Gr72-EG2-CB2 & $130 \pm 3.8$ & $2.9(97.1 \pm 1.1)$ & $74.8 \pm 1.1$ \\
Gr76-CV1(pc) & $119 \pm 3.8$ & $3.6(96.4 \pm 1.1)$ & $74.3 \pm 2.0$ \\
Gr70 & $95 \pm 4.5$ & $4.1(95.9 \pm 1.1)$ & $73 \pm 3.2$ \\
\hline \hline Note: ${ }^{*}$ Materials: Composition of fillers, the rest percentage is resin matrix, ${ }^{* *}$ NPA $=$ Non-porous area $\%$
\end{tabular}

397

398

399

400

401

402

403

404

405

406

407

408

409

\section{CONCLUSIONS:}

In this research, the functional properties of materials and graphitic structures were investigated to determine the pivotal elements for the improvement of carbon polymer composite in highperformance fuel cell application. The maximum electrical conductivity of $221 \mathrm{~S} / \mathrm{cm}$ was achieved with ExG and $\mathrm{CB}$ and the maximum flexural strength of $52 \mathrm{MPa}$ from hybrid composite with graphite, $\mathrm{CF}$ and $\mathrm{CB}$ which elucidate the importance of optimization for desired properties. The main findings are

- The high pressure fabrication process and use of functional hybrid materials improve both the electrical and mechanical properties of the composite.

- The main critical factor especially for the improvement of electrical conductivity of carbon-epoxy composites are types of raw materials, combination of different sizes and use of nanofillers tailored by functional graphitic structure 
- Expandable graphite and expanded graphite can reduce the weight and thickness substantially by introducing layered structure which can incorporate to fabrication of a light-weight high-performance composite

- Porosity of the composite measured in a non-destructive way can be a very important factor which can be related to electrical conductivity, hence can be a determinant factor to the ultimate fuel cell performance

Overall, the fillers mainly control the conductivity through their graphitic functionalized structure whereas polymer matrix influences more to the flexural strength due to their inherent flexible properties. The electrical conductivity and mechanical strength need to be calibrated to achieve best targeted application requirements.

Acknowledgement: Authors acknowledge the funding support given by Ontario Research Excellence Fund (ORF-RE Round 7) and NSERC CRD. We like to thank Asbury Carbon for their generous help with carbon materials. We are also thankful to Total North America and Ford Motor Canada for their financial supports.

Appendix A. Supplementary data to this article can be found online at https://doi.org/10.1016/ j.compscitech.2021.108654

\section{Reference:}

[1] Boyac1 San FG, Tekin G. A review of thermoplastic composites for bipolar plate applications. Int. J. Energy Res. 2013; 37:283-309. https://doi.org/10.1002/er.3005

[2] Planes E., Flandin L., Alberola N. Polymer composites bipolar plates for PEMFCs. Energy Procedia 2012; 20:311-323. https://doi.org/10.1016/j.egypro.2012.03.031

[3] Kim M., Choe J., Lim J.W., Lee D.G. Manufacturing of the carbon/ phenol composite bipolar plates for PEMFC with continuous hot rolling process. Compos. Struct. 2015; 132:1122-1128. https://doi.org/10.1016/j.compstruct.2015.07.038

[4] Tsuchiya H., Kobayashi O. Mass production cost of PEM fuel cell by learning curve. Int. J. Hydrogen Energy 2004; 29:985-990. https://doi.org/10.1016/j.ijhydene.2003.10.011 
[5] Arvay A., French J., Wang J.-C., Peng X.-H., Kannan A.M. Nature inspired flow field designs for proton exchange membrane fuel cell. Int. J. Hydrogen Energy 2013; 38:3717-3726. https://doi.org/10.1016/j.ijhydene.2012.12.149

[6] Alaswad A., Baroutaji A., Achour A., Carton J., Al Makky A. Developments in fuel cell technologies in the transport sector. Int. J. Hydrogen Energy 2016; 41:16499-16508. https://doi.org/10.1016/j.ijhydene.2016.03.164

[7] Antunes R.A., de Oliveira M.C.L., Ett G., Ett V. Carbon materials in composite bipolar plates for polymer electrolyte membrane fuel cells: a review of the main challenges to improve electrical performance. J. Power Sources 2011; 196:2945-61. https://doi.org/10.1016/j.jpowsour.2010.12.041

[8] Pozio A., Zaza F., Masci A., Silva R.F. Bipolar plate materials for PEMFCs: A conductivity and stability study. J. Power Sources 2008; 179:631-639. https://doi.org/10.1016/j.jpowsour.2008.01.038

[9] Cheng X., Shi Z., Glass N., Zhang L., Zhang J., Song D., Liu Z-S., Wang H., Shen J. A review of PEM hydrogen fuel cell contamination: Impacts, mechanisms and mitigation. J. Power Sources 2007; 165:739756. https://doi.org/10.1016/j.jpowsour.2006.12.012

[10] Kelly M.J., Egger B., Fafilek G., Besenhard J.O., Kronberger H., Nauer G.E. Conductivity of polymer electrolyte membranes by impedance spectroscopy with microelectrodes. Solid State Ionics 2005; 176:2111-2114. https://doi.org/10.1016/j.ssi.2004.07.071

[11] Lim J.W., Kim M., Lee D.G. Conductive particles embedded carbon composite bipolar plates for proton exchange membrane fuel cells. Compos. Struct. 2014; 108:757-766. https://doi.org/10.1016/j.compstruct.2013.10.021

[12] Boyaci San FG, Okur O. The effect of compression molding parameters on the electrical and physical properties of polymer composite bipolar plates. Int. J. Hydrogen Energy 2017; 07:175-190. https://doi.org/10.1016/j.ijhydene.2017.07.175

[13] Boyaci San FG, Isik-Gulsac I, Okur O. Analysis of the polymer composite bipolar plate properties on the performance of PEMFC (polymer electrolyte membrane fuel cells) by RSM (response surface methodology). Energy 2013; 55:1067-75. https://doi.org/10.1016/j.energy.2013.03.076

[14] Shoyama M, Tomimura T, Mizutani S. Effect of hydrophilic properties of gas channel on water management of PEM fuel cells. J. Electrochem. Soc. 2009; 17:461-464. https://doi.org/10.1149/1.3142775 
[15] Shimpalee S, Lilavivat V, McCrabb H, Khunatorn Y, Lee HK, Lee WK. Investigation of bipolar plate materials for proton exchange membrane fuel cells. Int. J. Hydrogen Energy 2016; 41:13688-13696. https://doi.org/10.1016/j.ijhydene.2016.05.163

[16] Taherian R, Hadianfard MJ, Golikand .N. Manufacture of a polymer-based carbon nanocomposite as bipolar plate of proton exchange membrane fuel cells. Mater. Des. 2013b; 49:242-251. https://doi.org/10.1016/j.matdes.2013.01.058

[17] "DOE technical targets for polymer electrolyte membrane fuel cell components", Retrieved from US Govt. Office of efficiency and renewable energy website; https://www.energy.gov/eere/fuelcells/doe-technical$\underline{\text { targets-polymer-electrolyte-membrane-fuel-cell-components }}$

[18] Bokobza L, Bruneel J-L, Couzi M. Raman spectroscopic investigation of carbon-based materials and their composites-Comparison between carbon nanotubes and carbon black. Chem. Phy. Lett. 2013; 590:153-159. http://dx.doi.org/10.1016/j.cplett.2013.10.071

[19] Rahman M, Khastgir D, Aldalbahi AK. Carbon-containing polymer composites. Springer Nature 2019; 5:173. https://doi.org/10.1007/978-981-13-2688-2

[20] Sengupta R., Bhattacharya M., Bandyopadhyay S., Bhowmick A.K. A review on the mechanical and electrical properties of graphite and modified graphite reinforced polymer composites. Prog. Polym. Sci. 2011. 36:638-670. https://doi.org/10.1016/j.progpolymsci.2010.11.003

[21] Malard LM, Pimenta MA, Dresselhaus G, Dresselhaus MS. Raman spectroscopy in graphene. Phy. Reports. 2009; 473:51-87. https://doi.org/10.1016/j.physrep.2009.02.003

[22] Ferrari AC. Raman spectroscopy of graphene and graphite: Disorder, electron-phonon coupling, doping and nonadiabatic effects. Solid Stat. Comm. 2007; 143:47-57

[23] Strumpler R, Glatz-Reichenbach J. Conducting polymer composites. J. Electroceram. 1999; 3:329-46. https://doi.org/10.1023/A:1009909812823

[24] Wissler M. Graphite and carbon powders for electrochemical applications. J. Power Sources 2006; 156:142-150. https://doi.org/10.1016/j.jpowsour.2006.02.064

[25] Taherian R, Ghorbani MM. Investigation of the electrical properties of polymer/carbon composites exposed to joule heating and heat treatment. ECS J. Solid State Sci. Technol. 2017; 6:M3019-27. https://doi.org/10.1149/2.0051706jss 
[26] Antunes RA, de Oliveira MCL, Ett G, Ett V. Carbon materials in composite bipolar plates for polymer electrolyte membrane fuel cells: a review of the main challenges to improve electrical performance. J. Power Sources 2011; 196:2945-61. https://doi.org/10.1016/j.jpowsour.2010.12.041

[27] Janzen J (1975) On the critical conductive filler loading in antistatic composites. J Appl Phys 46:966-969

[28] Bigg DM, Bradhury JE (1981) Conducting polymers. In: Seymour RB (ed) Polymer science and technology, vol 15. Plenum, New York, p 13

[29] Medalia AI (1986) Electrical conduction in carbon black composites. Rubb Chem Technol 59:432-454

[30] Nelson JR (1986) Morphology of electrically conductive grades of carbon black. Carbon 24:115-121

[31] Gojny FH, Wichmann MHG, Fiedler B, Kinloch IA, Bauhofer W, Windle AH, Schulte K. Evaluation and identification of electrical and thermal conduction mechanisms in carbon nanotube/epoxy composites. Polymer 2006; 47:2036-2045. https://doi.org/10.1016/j.polymer.2006.01.029

[32] Dresselhaus M.S., Dresselhaus G. Intercalation compounds of graphite. Adv. Phys. 2002; 51:1-186. https://doi.org/10.1080/00018730110113644

[33] McRae E., Billaud D., Mareche J.F., Herold A. Basal plane resistivity of alkali metal-graphite compounds. Physica B 1980; 4:489-493. https://doi.org/10.1016/0378-4363(80)90283-1

[34] Derieth, T.; Bandlamudi, G.; Beckhaus, P.; Kreuz, C.; Mahlendorf, F.; Heinzel, A. Development of highly filled graphite compounds as bipolar plate materials for low and high temperature PEM fuel cells. J. New Mater. Electrochem. Syst. 2008, 11, 21-29

[35] Cunningham, B.D.; Baird, D.G. Development of bipolar plates for fuel cells from graphite filled wet-lay material and a compatible thermoplastic laminate skin layer. J. Power Sources 2007, 168, 418-425 https://doi.org/10.1016/j.jpowsour.2007.03.036

[36] Dihrab, S.S.; Sopian, K.; Alghoul, M.A.; Sulaiman, M.Y. Review of the membrane and bipolar plates materials for conventional and unitized regenerative fuel cells. Renew. Sustain. Energy Rev. 2009, 13, 1663-1668 https://doi.org/10.1016/j.rser.2008.09.029

[37] Feng, K.; Li, Z.; Sun, H.; Yu, L.; Cai, X.; Wu, Y.; Chu, P.K. Short communication C/CrN multilayer coating for polymer electrolyte membrane fuel cell metallic bipolar plates. J. Power Sources 2013, 222, 351-358 DOI: 10.1016/j.jpowsour.2012.08.087 
[38] Jung, H.; Huang, S.; Ganesan, P.; Popov, B.N. Performance of gold-coated titanium bipolar plates in unitized regenerative fuel cell operation. J. Power Sources 2009, 194, 972-975 DOI: 10.1016/j.jpowsour.2009.06.030

[39] San, F.G.; Okur, O. The effect of compression molding parameters on the electrical and physical properties of polymer composite bipolar plates. Int. J. Hydrogen Energy 2017, 42 DOI: 10.1016/j.ijhydene.2017.07.175

[40] Alaswad, A.; Benyounis, K.Y.; Olabi, A.G. Optimization Techniques in Material Processing. Engineering 2016 DOI: 10.1016/B978-0-12-803581-8.04004-2

[41] Chung C-Y, Chen S-K, Chiu P-J, Chang M-H, Hung, T-T, Ko T-H. Carbon film-coated 304 stainless steel as PEMFC bipolar plate. J. Power Sources 2008; 176:276-281 https://doi.org/10.1016/j.jpowsour.2007.10.022

[42] Ijaodola O, Ogungbemi E, Khatib FN, Wilberforce T, Ramadan M, Hassan ZE, Thompson J, Olabi AG. Evaluating the effect of metal bipolar plate coating on the performance of proton exchange membrane fuel cells. Energies 2018 DOI: 10.3390/en11113203

[43] Proch S, Stenstrom M, Eriksson L, Andersson J, Sjoblom G, Jansson A, Westlinder J. Coated stainless steel as bipolar plate material for anion exchange membrane fuel cells (AEMFCs). Int. J. Hydrogen Energy 2020; 45:1313-1324 https://doi.org/10.1016/j.ijhydene.2019.04.122

[44] Makkus RC, Janssen AHH, de Bruijn FA, Mallant RKAM. Use of stainless steel for cost competitive bipolar plates in the SPFC. J. Power Sources 2000; 86: 274-282. DOI: 10.1016/S0378-7753(99)00460-7

[45] Leng Y, Ming P, Yang D, Zhang C. Stainless steel bipolar plates for proton exchange membrane fuel cells: Materials, flow channel design and forming processes. J. Power Sources 2020; 451:227783 https://doi.org/10.1016/j.jpowsour.2020.227783

[46] R. Taherian, G.A. Nozad, M.J. Hadianfard. The effect of mold pressing pressure and composition on properties of nanocomposite bipolar plate for proton exchange membrane fuel cell Mater Des, 32 (2011), pp. 3883-3892 https://doi.org/10.1016/j.matdes.2011.02.059

[47] Cho E.A., Jeon U.S., Ha H.Y., Hong S.A., Oh I.H. Characteristics of composite bipolar plates for polymer electrolyte membrane fuel cells, J. Power Sources 2004; 125:178-182. https://doi.org/10.1016/j.jpowsour.2003.08.039 